$$
\begin{array}{r}
1 N-27 \\
205033 \\
15 P
\end{array}
$$

NASA Technical Memorandum 106475

\title{
Durability Evaluation of Ceramic Components Using CARES/LIFE
}

Noel N. Nemeth

Lewis Research Center

Cleveland, Ohio

Lynn M. Powers

Cleveland State University

Cleveland, Ohio

and

Lesley A. Janosik and John P. Gyekenyesi

Lewis Research Center

Cleveland, Ohio

Prepared for the

39th International Gas Turbine and Aeroengine Congress

sponsored by the American Society of Mechanical Engineers

The Hague, The Netherlands, June 13-16, 1994

-1NASA-TM-106475) DURABILITY

EVALUATION OF CERAMIC COMPONENTS

USING CARES/LIFE (NASA) $15 \mathrm{p}$

N94-24682

Unclas 


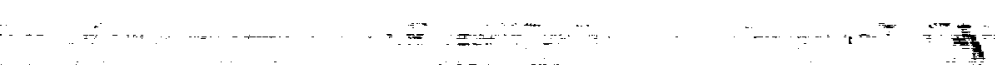

- 


\title{
DURABILITY EVALUATION OF CERAMIC COMPONENTS USING CARES/LIFE
}

\author{
Noel N. Nemeth \\ National Aeronautics and Space Administration \\ Lewis Research Center \\ Cleveland, Ohio 44135 \\ Lynn M. Powers \\ Department of Civil Enginnering \\ Cleveland State University \\ Cleveland, Ohio 44115 \\ Lesley A. Janosik and John P. Gyekenyesi \\ National Aeronautics and Space Administration \\ Lewis Research Center \\ Cleveland, Ohio 44135
}

\begin{abstract}
The computer program CARES/LIFE calculates the timedependent reliability of monolithic ceramic components subjected to thermomechanical and/or proof test loading. This program is an extension of the CARES (Ceramics Analysis and Reliability Evaluation of Structures) computer program. CARES/LIFE accounts for the phenomenon of subcritical crack growth (SCG) by utilizing the power law, Paris law, or Walker equation. The two-parameter Weibull cumulative distribution function is used to characterize the variation in component strength. The effects of multiaxial stresses are modeled using either the principle of independent action (PIA), the Weibull normal stress averaging method (NSA), or the Batdorf theory. Inert strength and fatigue parameters are estimated from rupture strength data of naturally flawed specimens loaded in static, dynamic, or cyclic fatigue. Application of this design methodology is demonstrated using experimental data from alumina bar and disk flexure specimens which exhibit SCG when exposed to water.
\end{abstract}

\section{NOMENCLATURE}

A

a

B

$\overline{\mathbf{C}}$

g

H surface area; material-environmental fatigue constant crack half length subcritical crack growth constant

Shetty's constant in mixed-mode fracture criterion g-factor step function ranking of ordered fracture data in statistical analysis stress intensity factor crack density coefficient Weibull modulus, or shape parameter material-environmental fatigue constant number of cycles cumulative failure probability cyclic fatigue parameter ratio of minimum to maximum effective stress in a load cycle period of one cycle time time-dependent scale parameter volume; crack velocity Cartesian coordinate directions crack geometry factor angle between $\sigma_{n}$ and the stress $\sigma_{1}$ angle between $\sigma_{n}$ projection and the stress $\sigma_{2}$ in plane perpendicular to $\sigma_{1}$ increment crack density function 3.1416 applied stress distribution

$\sigma_{0} \quad$ Weibull scale parameter

$\sigma_{1}, \sigma_{2}, \sigma_{3}$ tensor stress components; principal stresses $\left(\sigma_{1} \geq \sigma_{2} \geq \sigma_{3}\right)$ 
Subscripts:

$\begin{array}{ll}\text { B } & \text { Batdorf } \\ \text { c } & \text { cyclic; critical } \\ \text { ch } & \text { characteristic } \\ \text { cr } & \text { critical } \\ \text { d } & \text { dynamic fatigue } \\ \text { e,ef } & \text { effective } \\ \text { eq } & \text { equivalent } \\ \text { f } & \text { failure; fracture } \\ \text { I } & \text { crack opening mode } \\ \text { II } & \text { crack sliding mode } \\ \text { II } & \text { crack tearing mode } \\ \text { i } & \text { i'th } \\ \text { max } & \text { maximum } \\ \text { min } & \text { minimum } \\ \text { n } & \text { normal; normal stress averaging } \\ \text { S } & \text { surface } \\ \text { T } & \text { transformed } \\ \text { u } & \text { uniaxial } \\ \text { V } & \text { volume } \\ \text { w } & \text { Weibull } \\ \theta & \text { characteristic }\end{array}$

Superscripts:

- $\quad$ modified parameter

\section{INTRODUCTION}

Advanced ceramic components designed for gasoline, diesel, and turbine heat engines are leading to lower engine emissions, higher fuel efficiency, and more compact designs due to their low density and ability to retain strength at high temperatures. Ceramic materials are also used for wear parts (nozzles, valves, seals, etc.), cutting tools, grinding wheels, bearings, coatings, electronics, and human prostheses. Among the many requirements for the successful application of advanced ceramics are the proper characterization of material properties and the use of a mature and validated brittle material design methodology.

Ceramics are brittle and the lack of ductility leads to low strain tolerance, low fracture toughness, and large variations in observed fracture strength. The material as processed has numerous inherent randomly distributed flaws. The observed scatter in fracture strength is caused by the variable severity of these flaws. The ability of a ceramic component to sustain a load also degrades over time. This is due to a variety of effects such as oxidation, creep, stress corrosion, and cyclic fatigue. Stress corrosion and cyclic fatigue result in a phenomenon called subcritical crack growth (SCG). SCG initiates at an existing flaw and continues until a critical length is reached, causing cata- strophic crack propagation. The SCG failure mechanism is a load-induced phenomenon over time. It can also be a function of chemical reaction, environment, debris wedging near the crack tip, and deterioration of bridging ligaments. Because of this complexity, models that have been developed tend to be semi-empirical and approximate the behavior of subcritical crack growth phenomenologically.

The objective of this paper is to present a description of the integrated design computer program, CARES/LIFE ${ }^{(1)}$ (Ceramics Analysis and Reliability Evaluation of Structures LIFE prediction program). The theory and concepts presented in this paper reflect the capabilities of the CARES/LIFE program for time-dependent probabilistic design. To determine the validity of the design methodology utilized in this software, time-dependent reliability predictions from CARES/LIFE are compared with experimental data ${ }^{(2)}$ from uniaxially and biaxially loaded alumina flexure bars and disks which are known to exhibit slow crack growth in water.

\section{PROGRAM CAPABILIT AND DESCRIPTION}

Probabilistic component design involves predicting the probability of failure for a thermomechanically loaded component from specimen rupture data. Typically these experiments are performed using many simple geometry flexural or tensile test specimens. A static, dynamic, or cyclic load is applied to each specimen until fracture. Statistical strength and SCG (fatigue) parameters are then determined from these data. Using these parameters and the resuits obtained from a finite element analysis, the time-dependent reliability for a complex component geometry and loading is then predicted. Appropriate design changes are made until an acceptable probability of failure has been reached. This design methodology combines the statistical nature of strength-controlling flaws with the mechanics of crack growth to allow for multiaxial stress states, concurrent (simultaneously occurring) flaw populations, and scaling effects. These issues are addressed within the CARES/LIFE program.

CARES/LIFE predicts the probability of failure of a monolithic ceramic component as a function of service time. It assesses the risk that the component will fracture prematurely as a result of subcritical crack growth. The effect of proof testing components prior to service is also considered. CARES/LIFE is coupled to commercially available finite element programs such as ANSYS, ABAQUS, MSC/NASTRAN, and COSMOS/M. CARES/LIFE is an extension of the CARES ${ }^{(3,4)}$ program. It retains all of the capabilities of the previous CARES code, which include fast-fracture component reliability evaluation and Weibull parameter estimation from inert strength (without SCG contributing to failure) specimen data CARES/LIFE can estimate parameters that characterize SCG from specimen data as well.

Finite element heat transfer and linear-elastic stress analyses are used to determine the component's temperature and stress distributions. The reliability at each element is calculated assuming that randomly distributed volume flaws and/or surface flaws control the failure response. The probability of survival for each element is assumed to be a mutually exclusive event, and the overall component reliability is then the product of all the element survival probabilities. CARES/LIFE generates a data file 
containing element risk-of-rupture intensities (a local measure of reliability) for graphical rendering of the structure's critical regions.

CARES/LIFE describes the probabilistic nature of material strength, using the Weibull cumulative distribution function. The effect of multiaxial stresses on reliability is predicted using the principle of independent action (PLA), ${ }^{(5,6)}$ the Weibull normal stress averaging method (NSA), ${ }^{(7)}$ or the Batdorf theory ${ }^{(8,9)}$ The Batdorf theory combines the weakest link theory and linear elastic fracture mechanics (LEFM). Conventional fracture mechanics analysis requires that both the size of the critical crack and its orientation relative to the applied loads determine the fracture stress. The Batdorf theory includes the calculation of the combined probability of the critical flaw being within a certain size range and being located and oriented so that it may cause fracture. A user-selected flaw geometry and a mixed-mode fracture criterion are required to model volume- or surfacestrength-limiting defects. Mixed-mode fracture refers to the ability of a crack to grow under the combined actions of a normal load (opening mode) and shear load (sliding and tearing modes) on the crack face. CARES/LIFE includes the total strain energy release rate fracture criterion, which assumes a crack will extend in its own plane (coplanar). ${ }^{(9)}$ Out-of-plane crack extension criteria are approximated by a simple semiempirical equation. (10,11) Available flaw geometries include the Griffith crack, penny-shaped crack, semicircular crack, and notched crack. The Batdorf theory is equivalent to the probabilistic multiaxial theories proposed by Evans ${ }^{(12)}$ and Matsuo. ${ }^{(13)}$

Subcritical crack growth is difficult to model, because it is a complex phenomenon often involving a combination of failure mechanisms. Existing models usually involve empirically derived crack propagation laws that describe the crack growth in terms of the stress intensity factor at the crack tip plus additional parameters obtained from experimental data.

In CARES/LIFE, the relations describing subcritical crack growth are directly incorporated into the PLA, NSA, and Batdorf theories. Subcritical crack growth is modeled with the power law, ${ }^{(14,15)}$ the Paris law, ${ }^{(16)}$ and the Walker law ${ }^{(17,18)}$ for static and constant-amplitude cyclic loading. These laws use experimentally determined parameters which are material- and environment-sensitive. The power law is used to model stress corrosion cracking in materials such as glasses and alumina exposed to $\mathrm{H}_{2} \mathrm{O}$. Elevated-temperature slow crack growth of silicon nitrides, silicon carbides, and alumina also follows power law behavior.

Some polycrystalline ceramics are prone to strength degradation due to mechanical damage induced by cyclic loading. The Paris and Walker laws have been suggested as models to account for this behavior. ${ }^{(18)}$ The Walker equation is functionally similar to the Paris equation with additional terms to account for the effect of the R-ratio (minimum cycle stress to maximum cycle stress) on lifetime.

CARES/LIFE is capable of predicting the change in a surviving component's reliability after proof testing is performed. Proof testing is the loading of all components prior to service to eliminate those which may fail prematurely. The components that survive the proof test will have a lower (attenuated) risk of failure in service. In CARES/LIFE the attenuated failure probability is calculated using the PIA, the Weibull normal stress averaging, and the Batdorf theories. The Batdorf model is used to calculate the attenuated failure probability when the proof test load and the service load are not in line or have different multiaxial stress states. This feature is useful when the proof test does not identically simulate the actual service conditions on the component. The durations of the proof test and the service load are also considered in the analysis.

Predicted lifetime reliability of structural ceramic components depends on Weibull and fatigue parameters estimated from widely used tests involving flexural or tensile specimens. CARES/LIFE estimates fatigue parameters from naturally flawed specimens ruptured under static, cyclic, or dynamic (constant stress rate) loading. Fatigue and Weibull parameters are calculated from rupture data of three-point and four-point flexure bars, as well as tensile specimens. For other specimen geometries, a finite element model of the specimen is also required when estimating these parameters.

\section{THEORY}

Time-dependent reliability is based on the mode I equivalent stress distribution transformed to its equivalent stress distribution at time $t=0$. Investigations of mode I crack extension ${ }^{(19)}$ have resulted in the following relationship for the equivalent mode I stress intensity factor

$$
K_{\text {Ieq }}(\Psi, t)=\sigma_{\text {leq }}(\Psi, t) Y \sqrt{a(\Psi, t)}
$$

where $\sigma_{\text {leg }}(\Psi, t)$ is the equivalent mode I stress on the crack, $Y$ is a function of crack geometry, $a(\Psi, t)$ is the appropriate crack length, and $\Psi$ represents a location $(x, y, z)$ within the body and the orientation $(\alpha, \beta)$ of the crack. In some models such as the Weibull and PIA, $\Psi$ represents a location only. $Y$ is a function of crack geometry; however, herein it is assumed constant with subcritical crack growth. Crack growth as a function of the equivalent mode I stress intensity factor is assumed to follow a power law relationship

$$
\frac{\mathrm{da}(\Psi, t)}{\mathrm{dt}}=A K_{\mathrm{Ieq}}^{\mathrm{N}}(\Psi, t)
$$

where $\mathrm{A}$ and $\mathrm{N}$ are material/environmental constants. The transformation of the equivalent stress distribution at the time of failure, $t=t_{f}$, to its critical effective stress distribution at time $t=0$ is expressed as $(20,21)$

$$
\sigma_{\text {Ieq, }, 0}\left(\Psi, t_{f}\right)=\left[\frac{\int_{0}^{t_{f}} \sigma_{\text {Ieq }}^{N}(\Psi, t) d t}{B}+\sigma_{\text {leq }}^{N-2}\left(\Psi, t_{f}\right)\right]^{\frac{1}{(N-2)}}
$$


where

$$
\mathrm{B}=\frac{2}{A \mathrm{Y}^{2} \mathrm{~K}_{\mathrm{IC}}^{\mathrm{N}-2}(\mathrm{~N}-2)}
$$

is a material/environmental fatigue parameter, $\mathrm{K}_{\mathrm{Ic}}$ is the critical stress intensity factor, and $\sigma_{\mathrm{Ieq}}\left(\Psi, \mathrm{t}_{\mathrm{f}}\right)$ is the equivalent stress distribution in the component at time $t=t_{f}$. The dimensionless fatigue parameter $\mathrm{N}$ is independent of fracture criterion. $\mathrm{B}$ is adjusted to satisfy the requirement that for a uniaxial stress state, all models produce the same probability of failure. The parameter B has units of stress ${ }^{2} \times$ time.

\section{Volume Flaw Analysis}

The probability of failure for a ceramic component using the Batdorf model ${ }^{(8,9,22)}$ for volume flaws is

$$
P_{\mathrm{fV}}=1-\exp \left\{-\int_{V}\left[\int_{0}^{\sigma_{e_{\max }}} \frac{\Omega}{4 \pi} \frac{d \eta_{\mathrm{V}}\left(\sigma_{\mathrm{cr}}\right)}{d \sigma_{\mathrm{cr}}} d \sigma_{\mathrm{cr}}\right] d V\right\}
$$

where $V$ is the volume, $\eta_{\mathrm{V}}$ is the crack density function, $\sigma_{e}$ is the maximum value of $\sigma_{\text {Ieq, } 0}$ for all values of $\Psi$, and $\Omega$ is the area of a solid angle projected onto a unit radius sphere in principal stress space containing all crack orientations for which the effective stress is greater than or equal to the critical mode I strength, $\sigma_{\mathrm{cr}}$. The crack density distribution is a function of the critical effective stress distribution. For volume flaw analysis, the crack density function is expressed as

$$
\eta_{\mathrm{V}}\left(\sigma_{c r}(\Psi)\right)=\mathbf{k}_{\mathrm{BV}} \sigma_{\mathrm{cr}}^{\mathrm{m}_{\mathrm{V}}}
$$

where $\mathrm{k}_{\mathrm{BV}}$ and $\mathrm{m}_{\mathrm{V}}$ are material constants. The solid angle is expressed as

$$
\Omega=\int_{0}^{2 \pi} \int_{0}^{\pi} H\left(\sigma_{\text {Ieq }, 0}, \sigma_{c r}\right) \sin \alpha d \alpha d \beta
$$

where

$$
H\left(\sigma_{\text {Ieq, }, 0}, \sigma_{\mathrm{cr}}\right)= \begin{cases}1 & \sigma_{\text {Ieq, } 0} \geq \sigma_{\mathrm{cr}} \\ 0 & \sigma_{\mathrm{Ieq}, 0}<\sigma_{\mathrm{cr}}\end{cases}
$$

and $\alpha$ and $\beta$ are the radial and azimuthal angles, respectively, on the unit radius sphere. The transformed equivalent stress $\sigma_{\text {Ieg, } 0}$ is dependent on the appropriate fracture criterion, crack shape, and time to failure, 4 . Equation (4) can be simplified by performing the integration of $\sigma_{\mathrm{cr}}{ }^{(22)}$ yielding the time-dependent probability of failure for volume flaw analysis
$P_{f V}\left(t_{f}\right)=1-\exp \left[-\frac{k_{B V}}{2 \pi} \int_{V} \int_{0}^{2 \pi} \int_{0}^{\pi} \sigma_{\text {leq, }}^{m_{Y}}\left(\Psi, t_{f}\right) \sin \alpha d \alpha d \beta d V\right]$

Fracture criteria and crack shapes available for time-dependent analysis are identical to those used for fast fracture analysis in CARES. ${ }^{(3,4)}$ These fracture criteria include Weibull nomal stress averaging (a shear-insensitive case of the Batdorf theory), the total coplanar strain energy release rate, and the noncoplanar crack extension (Shetty) criterion.

For a stressed component, the probability of failure for volume flaw analysis is calculated from equation (7). The finite element method enables discretization of the component into incremental volume elements. CARES/LIFE evaluates the reliability at the Gaussian integration points of the element or, optionally, at the element centroid. Subelement volume is defined as the contribution of the integration point to the element volume in the course of the numerical integration procedure. The volume of each subelement (corresponding to a Gauss integration point) is calculated using shape functions inherent to the element type ${ }^{(4)}$. Assuming that the probability of survival for each element is a mutually exclusive event, the overall component reliability is then the product of all the calculated element (or subelement) survival probabilities.

\section{Surface Flaw Analysis}

The probability of failure for a ceramic component using the Batdorf model ${ }^{(8,9,22)}$ for surface flaws is

$$
P_{\mathrm{tS}}=1-\exp \left\{-\int_{\mathrm{A}}\left[\int_{0}^{\sigma_{e_{\max }}} \frac{\omega}{\pi} \frac{d \eta_{S}\left(\sigma_{\mathrm{cr}}\right)}{d \sigma_{\mathrm{cr}}} d \sigma_{\mathrm{cr}}\right] \mathrm{dA}\right\}
$$

where $A$ is the surface area, $\eta_{S}$ is the crack density function, $\sigma_{e}$ is the maximum value of $\sigma_{l e g, 0}$ for all values of $\Psi$, and $\omega$ is the arc length of an angle $\alpha$ projected onto a unit radius semicircle in principal stress space containing all of the crack orientations for which the effective stress is greater than or equal to the critical stress. Analogous to the argument for volume flaws, equation (8) can be reformulated, yielding ${ }^{(22)}$

$$
P_{f S}\left(t_{f}\right)=1-\exp \left[-\frac{k_{B S}}{\pi} \int_{A} \int_{0}^{\pi} \sigma_{\text {leq, }, 0}^{m_{S}}\left(\Psi, t_{f}\right) d \alpha d A\right]
$$

The transformed equivalent stress $\sigma_{\text {leq, } 0}$ is dependent on the appropriate fracture criterion, crack shape, and time to failure, 4. The fracture criteria and crack shapes available for timedependent analysis are identical to those used for fast fracture analysis. These fracture criteria include Weibull normal stress averaging (a shear-insensitive case of the Batdorf theory), the 
total coplanar strain energy release rate, and the noncoplanar crack extension (Shetty) criterion.

The finite element method enables discretization of the surface of the component into incremental area elements. CARES/LIFE evaluates the failure probability at the Gaussian integration points of shell elements or, optionally, at the element centroids. The area of each subelement (corresponding to a Gaussian integration point) is calculated using shape functions inherent to the element type ${ }^{(4)}$. Assuming that the probability of survival for each element is a mutually exclusive event, the overall component reliability is then the product of all the calculated element (or subelement) survival probabilities.

\section{Static Fatigue}

Static fatigue is defined as the application of a nonvarying load over time. For this case the mode I equivalent stress, $\sigma_{\text {Ieq }}(\Psi, t)$, is independent of time and is thus denoted by $\sigma_{\text {Ieq }}(\Psi)$. Integrating equation (3) with respect to time yields

$$
\sigma_{\text {Ieq }, 0}\left(\Psi, t_{f}\right)=\sigma_{\text {Ieq }}(\Psi)\left[\frac{t_{f} \sigma_{\text {Ieq }}^{2}(\Psi)}{B}+1\right]^{\frac{1}{N-2}}
$$

\section{Dynamic Fatique}

Dynamic fatigue is defined as the application of a constant stress rate $\sigma(\Psi)$ over a period of time, t. Assuming the applied stress is zero at time $t=0$, then

$$
\sigma_{\operatorname{Ieg}}(\Psi, t)=\sigma(\Psi) t
$$

Substituting equation (11) into equation (3) results in an expression for effective stress at the time of failure

$$
\sigma_{\text {Ieq }, 0}(\Psi)=\left[\frac{\sigma_{\text {Ieq }}^{N}\left(\Psi, t_{f}\right) t_{f}}{(N+1) B}+\sigma_{\text {leq }}^{N-2}\left(\Psi, t_{f}\right)\right]^{\frac{1}{N-2}}
$$

\section{Cyclic Fatigue}

Cyclic fatigue is defined as the repeated application of a loading sequence. Analysis of the time-dependent probability of failure for a component subjected to various cyclic boundary load conditions is simplified by transforming that type of loading to an equivalent static load. The conversion satisfies the requirement that both systems will cause the same crack growth. ${ }^{(23)}$ Implicit in this conversion is the validity of equation (2) for describing the crack growth. The probability of failure is obtained with respect to the equivalent static state.

Evans $^{(24)}$ and Mencik ${ }^{(23)}$ defined $g$-factors, $g(\Psi)$, for various types of cyclic loading, that are used to convert the cyclic load pattern to an equivalent static load. For periodic loading, $T$ is the time interval of one cycle, and $\sigma_{\operatorname{leg}}(\Psi)$ is the equivalent static stress acting over the same time interval, $\mathrm{t}_{1}$, as the applied cyclic stress, $\sigma_{\text {legc }}(\Psi, t)$, at some location $\Psi$. The equivalent static stress is related to the cyclic stress by

$$
\begin{aligned}
\sigma_{\text {Ieq }}^{N}(\Psi) t_{1}=\int_{0}^{t_{1}} \sigma_{\text {Ieqc }}^{N}(\Psi, t) d t & =t_{1}\left[\frac{\int_{0}^{T} \sigma_{\text {Ieqc }}^{N}(\Psi, t) d t}{T}\right] \\
& =g(\Psi) \sigma_{\text {leqc }}^{N}(\Psi) t_{1}
\end{aligned}
$$

The CARES/LIFE program uses the maximum cyclic stress, $\sigma_{\text {Iegc } \max }(\Psi)$, of the periodic load as a characteristic value to normalize the $g$-factor. For a periodic load over a time $t_{1}$, the mode I static equivalent stress distribution is

$$
\sigma_{\text {Ieq, }, 0}\left(\Psi, t_{f}\right)=\sigma_{\text {Ieqc }}(\Psi)\left[\frac{g(\Psi) t_{f} \sigma_{\text {Iequ }}^{2}(\Psi)}{B}+1\right]^{\frac{1}{N-2}}
$$

The use of $g$-factors for determining component life is an unconservative practice for materials prone to cyclic damage. The Walker equation, (17) which has traditionally been used in metals design, has been suggested as a model of fatigue damage for some ceramic materials. ${ }^{(18)}$ The Walker equation describes the crack growth increment per cycle, $n$, as

$$
\frac{\mathrm{da}(\Psi, \mathrm{n})}{\mathrm{dn}}=A \mathrm{~K}_{\mathrm{Ie} \max }^{\mathrm{N}-Q_{(\Psi, n)}} \Delta \mathrm{K}_{\mathrm{IL}}^{\mathrm{Q}_{\mathrm{m}}}(\Psi, \mathrm{n})
$$

where

$$
K_{\mathrm{I}_{\max }}(\Psi, n)=\sigma_{\mathrm{Ieg} x_{\max }}(\Psi, n) Y \sqrt{\mathrm{a}(\Psi, n)}
$$

and $\Delta \mathrm{K}_{\mathrm{Ie}}(\Psi, n)$ represents the range of the stress intensity factor over the load cycle. The subscripts $\max$ and $\min$ indicate the maximum and minimum cycle stress, respectively. The cyclic fatigue parameters $A, N$, and $Q$ are experimentally determined. The Walker equation reduces to the Paris law ${ }^{(16)}$ when $\mathrm{N}$ and $\mathrm{Q}$ are equal in value. The integration of Eq. (15) parallels that of Eq. (2), yielding the cyclic fatigue equivalent stress distribution

$$
\begin{array}{r}
\sigma_{\text {leqc }, 0}\left(\Psi, n_{f}\right)=\left[\frac{\int_{n=0}^{n_{f}}[1-R(\Psi, n)]^{Q} \sigma_{\text {Ieqc }}^{N}(\Psi, n) d n}{B}\right. \\
\left.+\sigma_{\text {Iequ }}^{N-2}\left(\Psi, n_{f}\right)\right]^{\frac{1}{N-2}}
\end{array}
$$

where $R(\Psi, n)$ is the ratio of the minimum to maximum cyclic stress, $n_{f}$ is the number of cycles to failure, and $B$ is now expressed in units of stress ${ }^{2} \times$ cycle. The parameters $B$ and $N$ are determined from cyclic data. 
Evaluation of Fatigue Parameters from Inherently Flawed Specimens

Lifetime reliability of structural ceramic components depends on the history of the loading, the component geometry, the distribution of pre-existing flaws, and the parameters that characterize subcritical crack growth. These crack growth parameters must be measured under conditions representative of the service environment. When determining fatigue parameters from rupture data of naturally flawed specimens, the statistical effects of the flaw distribution must be considered along with the strength degradation effects of subcritical crack growth. In the following discussion, fatigue parameter estimation methods are described for surface flaw analysis using the power law formulation for constant stress rate loading (dynamic fatigue). Analogous formulations for volume flaws, static fatigue, and cyclic fatigue have also been developed. ${ }^{(1)}$

For the uniaxial Weibull distribution the probability of failure is expressed as

$$
P_{\mathrm{fS}}\left(t_{f}\right)=1-\exp \left[-k_{w S} \int_{A} \sigma_{1,0}^{m_{S}}(\Psi) d A\right]
$$

where $\Psi$ represents a location $(x, y)$ and $\sigma_{1,0}$ denotes the transformed uniaxial stress analogous to $\sigma_{\text {legc, }, 0}$ as defined in equation (13). The Weibull crack density coefficient is given by

$$
\mathbf{k}_{\mathrm{wS}}=\frac{1}{\sigma_{\mathrm{oS}}^{\mathrm{m}_{\mathrm{s}}}}
$$

The Weibull scale parameter, $\sigma_{0 S}$, corresponds to the stress level where 63.21 percent of specimens with unit area would fail and has units of stress $x$ area $1 / n^{2}$. CARES/LIFE normalizes the various fracture criteria to yield an identical probability of failure for the uniaxial stress state. This is achieved by adjusting the fatigue constant $B$. For the uniaxial Weibull model this adjusted value is denoted by $B_{w}$ and for the Batdorf model it is denoted by $B_{B}$. From the dynamic fatigue equation (12), substituting $B_{w S}$ for $B, N_{S}$ for $N$, the uniaxial stress $\sigma_{1}$ for $\sigma_{\text {Ieq, }}$, and rearranging equation (17) while assuming that

$$
\frac{\sigma_{1}^{2}\left(\Psi, t_{f}\right) t_{f}}{\left(N_{S}+1\right) B_{w S}}>>1
$$

the median behavior of the experimental dynamic fatigue data can be described by

$$
\sigma_{\mathrm{f}_{0.5}}=\mathrm{A}_{d} \sigma^{1 /\left(\mathrm{N}_{\mathrm{s}}+1\right)}
$$

where $\sigma_{\mathfrak{f}_{0.5}}$ is the median rupture stress of the specimen and $\delta$ represents the stress rate at the location of maximum stress. The constant $A_{d}$ is

$$
\mathbf{A}_{\mathrm{d}}=\left\{\frac{\left(\mathbf{N}_{\mathrm{S}}+1\right) \mathbf{B}_{\mathrm{wS}} \sigma_{\mathrm{oS}}^{\mathbf{N}_{\mathrm{S}}-2}}{\left[\frac{\mathrm{A}_{\mathrm{ef}}}{\ln \left(\frac{1}{1-0.50}\right)}\right]^{1 / \tilde{\mathrm{m}}_{\mathrm{S}}}}\right\}^{\left.1 / \mathrm{N}_{\mathrm{s}}+1\right)}
$$

where

$$
\bar{m}_{s}=\frac{m_{s}}{N_{s}-2}
$$

The constants $A_{d}$ and $A_{e f}$ are obtained by equating risks of rupture. $A_{e f}$ is a modified effective area required for the timedependent formulation. For the uniaxial Weibull distribution, the expression for the modified effective area is

$$
A_{e f}=\int_{A}\left(\frac{\sigma_{1}\left(\Psi, t_{f}\right)}{\sigma_{f}}\right)^{\overline{\bar{m}}_{S} N_{S}} \mathrm{dA}
$$

where $\sigma_{1}\left(\Psi, t_{f}\right)$ denotes the maximum principal stress distribution. For multiaxially stressed components, the Batdorf technique is used to evaluate fatigue parameters. The analogous formulation for $A_{e f}$ is then

$$
A_{e f}=\frac{2 \overline{\mathbf{k}}_{\mathrm{BS}}}{\pi} \int_{\mathrm{A}}\left[\int_{\int^{2}}^{\pi}\left(\frac{\sigma_{\mathrm{leq}}\left(\Psi, \mathrm{t}_{\mathrm{f}}\right)}{\sigma_{\mathrm{f}}}\right)^{\overline{\mathrm{m}}_{\mathrm{S}} \mathrm{N}_{\mathrm{S}}} \mathrm{d} \alpha\right] \mathrm{dA}
$$

where the normalized Batdorf crack density coefficient is $\overline{\mathbf{k}}_{\mathrm{BS}}=\mathbf{k}_{\mathrm{BS}} / \mathbf{k}_{\mathrm{wS}}$. Equation (21) is applicable except that $\mathrm{B}_{\mathrm{BS}}$ replaces $B_{w 5}$. The relationship between $B_{B S}$ and $B_{w S}$ for a uniaxial load is established by equating the risk of rupture of the Batdorf model with that of the uniaxial Weibull model ${ }^{(1)}$

$$
\frac{B_{w S}}{B_{B S}}=\left[\frac{\pi \int_{A}^{\sigma_{1} \sigma_{S} N_{S}}\left(\Psi, t_{f}\right) d A}{2 \dot{k}_{B S} \iint_{A}^{\frac{\pi}{2}} \sigma_{\text {leq }}^{\tilde{m}_{S} N_{S}}\left(\Psi, t_{f}\right) d \alpha d A}\right]^{1 / m_{S}}
$$

As $\mathrm{N}_{\mathrm{S}}$ becomes large, equation (24) approaches unity.

The terms $A_{d}$ and $N_{S}$ in equation (21) are determined from experimental data. Taking the logarithm of equation (20) yields

$$
\ln \sigma_{f_{0 S}}=\ln A_{d}+\frac{1}{N_{S}+1} \ln \sigma
$$

Linear regression analysis of the experimental data is used to solve equation (25). The median value method is based on least squares linear regression of median data points for various stress 
rates. Another technique uses least squares linear regression on all the data points. A third option for estimating fatigue parameters is a modification to a method used by Jakus. ${ }^{(25)}$ In this procedure, fatigue parameters are determined by minimizing the median deviation of the logarithm of the failure stress. The median deviation is the mean of the residuals, where the residual is defined as the absolute value of the difference between the logarithm of the failure stress and the logarithm of the median value. In CARES/LIFE this minimization is accomplished by maximizing $\overline{\mathbf{m}}_{S}\left(\mathrm{~N}_{S}+1\right)$ estimated from the data versus the fatigue exponent.

To obtain $A_{d}$ based on the median line of the distribution the following steps are taken. Experimental data at a sufficient number of discrete levels of applied stressing rate are transformed to equivalent failure times $t_{T i}$ at a fixed stress rate $\sigma_{\mathrm{T}}$ (equating failure probabilities using equation (17))

$$
t_{T i}=t_{f i}\left(\frac{\sigma_{i}}{\sigma_{T}}\right)^{N_{S} /\left(N_{S}+1\right)}
$$

where the subscript $T$ indicates a transformed value, the subscript $i$ denotes each observed data number, and $t_{\mathrm{fi}}=\sigma_{\mathrm{fi}} / \sigma_{\mathrm{i}}$. In CARES/LIFE the value of $\sigma_{\mathrm{T}}$ is taken as the lowest level of stressing rate in the data set. With the data defined by a single Weibull distribution, parameter estimation is performed on the transformed data using

$$
P_{\mathrm{fi}}=1-\exp \left[-\left(\frac{t_{T i}}{t_{T \theta S}}\right)^{\tilde{m}_{S}\left(N_{s}+1\right)}\right]
$$

where the characteristic time is

$$
t_{T \theta S}=\left[\frac{\left(N_{S}+1\right) B \sigma_{o S}^{N_{S}-2}}{A_{e f}^{1 / m_{S}} \dot{\sigma}_{T}^{N_{S}}}\right]^{1 /\left(N_{S}+1\right)}
$$

CARES/LIFE performs least squares or maximum likelihood Weibull parameter estimation as described in $\mathrm{Pai}^{(26)}$ to solve equation (27) for $\overline{\mathbf{m}}_{\mathrm{S}}\left(\mathrm{N}_{\mathrm{S}}+1\right)$ and $\mathrm{t}_{\mathrm{T} \text {. }}$. Substituting $\bar{\sigma}_{\mathrm{T}}$ for $\sigma$ in equation (20) and solving for the rupture stress in equation (27) corresponding to a $50 \%$ probability of failure, $\sigma_{\mathrm{T}_{0.50}}$, yields

$$
A_{d}=t \operatorname{T\theta s}\left\{\sigma_{T}^{N_{S}}\left[\ln \left(\frac{1}{1-0.50}\right)\right]^{1 / \tilde{m}_{s}}\right\}^{1 /\left(N_{S}+1\right)}
$$

This value of $A_{d}$ is used with the fatigue exponent $N_{S}$ estimated either with the least squares (using all experimental rupture stresses) or median deviation method. The fatigue constant $B$ is obtained from equations (21) or (28).

\section{EXAMPLE}

This example demonstrates the use of CARES/LIFE to predict the time-dependent reliability of components under multiaxial loads. The data for this example is from experimental work performed by Chao and Shetty ${ }^{(2)}$ on alumina disks and bars exposed to water at room temperature. Chao and Shetty investigated the relationship between stress state and timedependent strength degradation, specifically to determine if strength degradation due to slow crack growth in biaxial flexure can be predicted from inert fracture stresses and dynamic fatigue assessed in simple uniaxial tests. Time-dependent reliability predictions for the alumina from CARESILIFE are compared to the results obtained by Chao and Shetty.

Details regarding specimen preparation and testing are given in reference 2 . Two batches of an alumina ceramic were purchased from the same vendor. The first batch was in the form of plates $(127 \times 127 \times 5 \mathrm{~mm})$ and rods $(50.8 \mathrm{~mm}$ diameter, $76.2 \mathrm{~mm}$ length). The plates and rods were made from the same powder lot with identical isostatic pressing and sintering conditions. The second batch of alumina, in the form of rods, was purchased subsequently to examine dynamic fatigue under biaxial stresses. This material had identical chemistry and preparation as the first batch. The measured properties of the first batch include a fracture toughness, $\mathrm{K}_{\mathrm{Ic}}$, of $4.13 \mathrm{MPa} \cdot \sqrt{\mathrm{m}}$, Young's modulus, $\mathrm{E}$, of $297.2 \mathrm{GPa}$, and a Poisson's ratio, $v$, of 0.23 .

Bar specimens were cut from the plate stock and disks were cut from the rod stock. Specimens were either tested in a dry nitrogen environment at $100 \mathrm{MPa} / \mathrm{s}$ to obtain inert (fast-fracture) strengths, or in deionized water at various stress rates to obtain the time-dependent fracture strengths. The specimens were carefully prepared to minimize machining damage or failure from edge flaws. The uniaxial specimens were nominally $3 \times 4 \times 45 \mathrm{~mm}$. These specimens were loaded in either four-point flexure with an outer support span of $40 \mathrm{~mm}$ and an inner load span of $20 \mathrm{~mm}$, or in three-point flexure using a $40 \mathrm{~mm}$ support span. The disk specimens were nominally $3.175 \mathrm{~mm}$ in thickness and $50.8 \mathrm{~mm}$ in diameter. They were loaded under uniform pressure on one face and supported on the other face by 40 freely rotating ball bearings spaced uniformly along a $49.53 \mathrm{~mm}$ diameter circle. Fractography showed that all specimens broke due to a single population of randomly oriented surface flaws.

Table 1 lists the fast-fracture Weibull parameters, estimated using the maximum likelihood method, for the various specimen configurations and loads. The values shown correlate very well to those of reference 2 for the Weibull shape parameter and characteristic strength. The results for the $90 \%$ confidence intervals differ somewhat from reference 2 due to the methods of estimation. CARES/LIFE uses the technique from Thoman, Bain and Antle ${ }^{(27)}$, while reference 2 uses a bootstrap technique. The $90 \%$ confidence interval on the Weibull modulus significantly overlaps for both bar and disk tests. This is an indication that the strength response is controlled by the same flaw population. Confidence bands on the characteristic strength may only be compared for identical specimen loading and geometry due to the size effect. The confidence intervals obtained for the two disk tests using CARES/LIFE are shown to overlap. The large confidence interval for the batch 2 specimens is due to the small sample size of 7 specimens. In reference 2 the discrepancies in average strength between batch 1 and batch 
2 disks were attributed to material processing differences. This will be further discussed.

Fatigue parameters were estimated from 4-point bend bar specimens loaded in dynamic fatigue in water. At least fifteen specimens each were tested at stress rates of $0.02,0.1,1.0,10.0$, and 100.0 MPa/s. Figure 1 shows a plot of the individual failure stresses of the 95 specimens tested. Superimposed on this figure are median lines and $5 \%$ and $95 \%$ confidence bounds on this data as estimated with the median deviation technique. Table 2 lists the estimated fatigue parameters using the median value, least squares, and median deviation techniques. The median deviation technique shows best agreement with Chao and Shetty for this case. In reference 2, the power law is used in the following form

$$
\frac{\mathrm{da}(\mathrm{t})}{\mathrm{dt}}=\mathrm{V}_{\mathrm{c}}\left(\frac{\mathrm{K}_{\mathrm{Ieq}}}{\mathrm{K}_{\mathrm{Ic}}}\right)^{\mathrm{N}}
$$

where $V_{c}$ is the critical crack velocity. The CARES/LIFE program is formulated using the fatigue constant $B$ and, therefore, $V_{c}$ is not explicitly calculated. However, for comparison, $V_{c}$ can be computed from CARES/LIFE results using the fracture strength relation ${ }^{(2)}$

$\sigma_{f}=\sigma\left[\frac{2 K_{l c}^{N_{S}}\left(N_{S}+1\right)}{V_{c} Y^{N_{S}}\left(N_{S}-2\right)} \sigma^{N_{s}}\left(a_{i}^{1-N_{S} / 2} \cdot a_{f}^{1-N_{s} / 2}\right)\right]^{\frac{1}{\left(N_{s}+1\right)}}$

where $a_{i}$ is initial crack size and $a_{f}$ is the crack size at failure. The subscript $S$ denotes surface-flaw-dependent properties. Assuming $a_{i} \gg a_{f}$ and rearranging the above expression yields

$$
\sigma_{\mathrm{f}}=\left[\frac{2 \mathrm{~K}_{\mathrm{lc}}^{\mathrm{N}_{\mathrm{s}}}\left(\mathrm{N}_{\mathrm{S}}+1\right) \mathrm{a}_{\mathrm{i}}^{1-\mathrm{N}_{\mathrm{S}} / 2}}{\mathrm{~V}_{\mathrm{c}} \mathrm{Y}^{N_{\mathrm{S}}}\left(\mathrm{N}_{\mathrm{S}}-2\right)}\right]^{\left.1 / \mathrm{N}_{\mathrm{S}}+1\right)} \sigma^{\frac{1}{N+1}}
$$

Equating equations (32) and (20) results in

$$
V_{c}=\frac{2 K_{I c}^{N_{S}}\left(N_{S}+1\right) a_{i}^{1-N_{S} / 2}}{A_{d}^{N_{S}+1} Y^{N_{S}}\left(N_{S}-2\right)}
$$

The initial crack length $a_{j}$ and fatigue constant $A_{d}$ are evaluated here for a failure probability of 50 percent. The crack geometry factor $Y$ for a semicircular crack is $1.366^{(3)}$. Crack length $a_{i}$ was determined from equation (1) using the strength determined from inert testing (Table 1) for a 50 percent probability of failure. Chao and Shetty ${ }^{(2)}$ estimated that $N_{S}$ was 40.7 and $V_{c}$ was 9.1 $\mathrm{m} / \mathrm{s}$ for $\mathrm{Y}$ equal to 1.24 . The differences between the various parameter estimates in CARES/LIFE and reference 2 are not considered significant. The fatigue velocity $\mathrm{V}_{\mathrm{c}}$ is particularly sensitive to $\mathrm{N}_{S}$ as shown in equation (33). Table 2 also lists the fatigue constants $B_{w S}$ and $B_{B S} . \quad B_{B S}$ is determined for a semicircular crack and noncoplanar crack extension with a shear sensitivity constant of $\bar{C}=0.82^{(3)}$. The differences between $B_{w S}$ and $B_{B S}$ are small since $N_{S}$ is relatively large. Finally, the Weibull modulus can be directly estimated from the fatigue data using the relation $\tilde{m}_{S}=m_{S} /\left(N_{S}-2\right)$ when $N_{S}$ and $\tilde{m}_{S}$ are known. For example, using the median deviation method $\mathrm{m}_{S}=25.0$, which is consistent with the results shown in Table 1.

To obtain disk specimens for dynamic fatigue tests, a second batch of material (of identical dimensions as the first material batch) was secured by Chao and Shetty ${ }^{(2)}$. Seven of these specimens were broken under inert conditions and a total of 35 specimens were broken at stressing rates of $0.02,0.1,10.0$, and $100.0 \mathrm{MPa} / \mathrm{s}$. Table 1 lists the fast-fracture Weibull parameters of the (batch 2) disks and Table 3 gives the estimates for the fatigue parameters. Table 3 shows only $B_{B S}$, since $B_{w S}$ is formulated only for the uniaxial stress state. Figure 2 shows a plot of the individual failure stresses as well as the median line and $5 \%$ and $95 \%$ confidence bounds estimated with the median deviation technique. One data point was flagged as an outlier (at $100 \mathrm{MPa} / \mathrm{s}$ ); however, it was not rejected and had little effect on the overall results. Batch 2 material showed a stronger than expected average strength relative to the batch 1 material. Chao and Shetty ${ }^{(2)}$ attributed this to a small increase of $K_{I c}$ in the material. Although batch 2 was unexpectedly strong, the rate of strength degradation was similar to that of the batch 1 four-point flexure data. Reference 2 reported that the $90 \%$ confidence intervals of $N_{S}$ for both batches showed significant overlap. This was further confirmed in Table 4, which shows the ratio of the natural logarithm of the characteristic strength of the batch 2 disks to the natural logarithm of the characteristic strength of the batch 1 four-point flexure specimens at each stressing rate (maximum likelihood estimates). If the rate of change of strength degradation were stress-state dependent, then the strength ratio would systematically change with stressing rate. However, Table 4 shows no such change. Therefore, the differences between fatigue exponents $\mathrm{N}_{S}$ in Table 3 and Table 2 appear to be reflecting expected statistical variation.

The effect of multiaxial stress states on the material is assessed by comparing the difference in inert strength between the uniaxially loaded four-point bend specimen and the biaxially loaded disk Assuming that small crack-like imperfections control the failure, the material strength in multiaxial stress states can be correlated to the effects of mixed-mode loading on the individual cracks. ${ }^{(8,9)}$ Shetty ${ }^{(11)}$ developed a simple equation describing the ability of a crack to extend under the combined actions of a normal and shear load on the crack face using an empirically determined parameter, $\overline{\mathbf{C}}$. For a semicircular crack this equation is ${ }^{(3)}$

$$
\sigma_{\mathrm{leq}}=\frac{1}{2}\left[\sigma_{\mathrm{n}}+\sqrt{\sigma_{\mathrm{n}}^{2}+3.301\left(\frac{\tau}{\overline{\mathrm{C}}}\right)^{2}}\right]
$$

where $\sigma_{n}$ and $\tau$ are the normal and shear stresses, respectively, acting on the flaw plane.

The failure response of the biaxial flexure specimens and the three-point flexure bars is predicted using the Weibull 
parameters (Table 1) and fatigue parameters (Table 2; median deviation results) estimated from the four-point flexure bar rupture tests. The prediction for the three-point bars is compared to experi-mental results to confurm the expected Weibull size effect. The disk prediction is compared to experimental results in order to make assertions regarding the effect of multiaxial stress states on the fast-fracture and fatigue fracture of the material.

For this analysis, the disk predictions are based on a finite element model of the disk as shown in Figure 3. Brick and wedge solid elements are used to model a $7.5^{\circ}$ sector of the disk and appropriate boundary conditions are applied corresponding to a $49.53 \mathrm{~mm}$ diameter ring support and a pressure load on one face. A gradient is imposed on the nodal spacing such that the smallest elements have the highest tensile stresses. This is required to obtain a satisfactory convergence of the reliability solution and is independent of the mesh size needed to obtain accurate nodal stresses. To perform surface flaw reliability analysis quadrilateral and triangular shell elements are attached to the surface nodes on the disk tensile face in order to obtain surface stresses and areas. The shell elements are very thin and have membrane properties only. These elements are such that they contribute negligible stiffness to the model. Verification of the accuracy of the finite element model is obtained by comparison to available closed form solutions. Chao and Shetty ${ }^{(2)}$ calibrated the applied pressure on the disk to the measured strain at the center of the disk. The strain calibration was used to correlate the fracture stress with the fracture pressure. The CARES/LIFE analysis uses these reported fracture stresses rather than the actual applied pressure on the disk. Reliability predictions for the three-point flexure bar are obtained from closed form solutions of the effective area. ${ }^{(1,3)}$

Probability of failure predictions are made for the disk and three-point bar in the fast-fracture condition and also for dynamic loading at a stressing rate of $1 \mathrm{MPa} / \mathrm{s}$ in water. The fracture strength distribution of dynamically (constant stress rate) loaded specimens is characterized by a Weibull distribution with a Weibull modulus, $m_{d s}$, of

$$
\mathbf{m}_{\mathrm{dS}}=\left(\frac{\mathbf{N}_{\mathrm{S}}+1}{\mathbf{N}_{\mathrm{S}}-2}\right) \mathbf{m}_{\mathrm{S}}
$$

For this analysis $m_{d S}$ has a value of 25.58. Table 5 lists the estimated Weibull parameters obtained from bars and disks loaded in this condition. In all cases the estimated Weibull modulus is somewhat higher than predicted; however, the predicted value was within the $90 \%$ confidence bounds. Table 5 shows that the Weibull modulus did increase from the inert condition, as expected. If the Weibull modulus value of $m_{S}=25.0$ obtained directly from the four-point fatigue data were considered, then $\mathrm{m}_{\mathrm{dS}}$ would be 26.9 , which is in better agreement with Table 5.

The CARES/LIFE program is designed to predict reliability for static fatigue or constant-amplitude cyclic loading. To predict reliability for dynamic loading, an equivalent static loading time is computed using the approach given in equation (16). In this case, the $\mathrm{g}$-factor is equal to $1 /\left(\mathrm{N}_{\mathrm{S}}+1\right)$ multiplied by the time to failure. Figures 4 and 5 are the resulting Weibull plots of these predictions for various levels of shear sensitivity parameter $\overline{\mathbf{C}}$. In Figure 4 a value of $\bar{C}$ of 0.82 is used which corresponds to an approximation of the maximum tangential stress mixed-mode fracture criterion. The dashed line in the figure denotes the results from reference 2 . The small differences indicated are mainly due to the different $\overline{\bar{C}}$ and crack geometry factor, $Y$, used and are not due to the different values used for the fatigue parameters. This figure also shows a good correlation between predicted and experimental results for the three-point flexure bars, which confirms the size effect expected in fast-fracture and fatigue. The CARES/LIFE prediction lines for the three-point flexure bars superimpose on the three-point bar prediction lines of reference 2 .

Figure 5 shows predictions for $\bar{C}$ values of $0.82,0.90$, and $\gg 1$ (solid, long dashed, and short dashed line, respectively). Since in this example the CARES/LIFE fracture predictions are normalized to the (uniaxial stress state) four-point flexure data, then the choice of a fracture criterion only effects the predictions for the (biaxial stress state) disks. The $\vec{C}$ values of 0.82 and much greater than one represent the extreme bounds on the expected mixed-mode shear sensitivity of the flaws in the material. The value of $\bar{C} \gg 1.0$ represents a shear-insensitive fracture criterion, while $\bar{C}=0.82$ is highly shear sensitive. The 0.90 value represents a choice of $\bar{C}$ that best fits to both inert and fatigue disk data. Optimizing $\bar{C}$ in this manner was not considered in reference 2. From this figure stress state effects are adequately accounted for, both in fast-fracture and subcritical crack growth conditions.

\section{CONCLUSION}

The use of structural ceramics for high-temperature applications depends on the strength, toughness, and reliability of these materials. Ceramic components can be designed for service if the factors that cause material failure are accounted for. This design methodology must combine the statistical nature of strength controlling flaws with fracture mechanics to allow for multiaxial stress states, concurrent flaw populations, and subcritical crack growth. This has been accomplished with the CARES/LIFE public domain computer program for predicting the time-dependent reliability of monolithic structural ceramic components. An example has been given to illustrate the use of this design methodology in CARES/LIFE for predicting the effects of component size, stress distribution, stress state, and subcritical crack growth on the lifetime reliability. Potential enhancements to the code include the capability for transient analysis, three-parameter Weibull statistics, creep and oxidation modeling, flaw anisotropy, threshold stress behavior, and parameter regression for multiple specimen sizes.

\section{REFERENCES}

1. Nemeth, N.N., Powers, L.M., Janosik, L.A., and Gyekenyesi, J.P., "Ceramics Analysis and Reliability Evaluation of Structures LIFE prediction program (CARES/LIFE) Users and Programmers Manual", TM-106316, to be published. 
2. Chao, L.Y., and Shetty, D.K., "Time-Dependent Strength Degradation and Reliability of an Alumina Ceramic Subjected to Biaxial Flexure," Life Prediction Methodologies and Data for Ceramic Materials, ASTM STP 1201, C.R. Brinkman, and S.F. Duffy, Eds., American Society for Testing and Materials, Philadelphia, 1993.

3. Nemeth, N.N., Manderscheid, J.M., Gyekenyesi, J.P., "Ceramics Analysis and Reliability Evaluation of Structures (CARES)", NASA TP-2916, Aug. 1990.

4. Powers, L.M., Starlinger, A., Gyekenyesi, J.P., "Ceramic Component Reliability With the Restructured NASAVCARES Computer Program", NASA TM-105856, Sept 1992.

5. Bameth, R.L., Connors, C.L., Hermann, P.C., and Wingfield, J.R., "Fracture of Brittle Materials Under Transient Mechanical and Thermal Loading," U.S. Air Force Flight Dynamics Laboratory, AFFDL-TR-66-220, 1967. (NTIS AD-649978)

6. Freudenthal, A.M., "Statistical Approach to Brittle Fracture," Fracture, Vol. 2: An Advanced Treatise, Mathematical Fundamentals, H. Liebowitz, ed., Academic Press, 1968 , pp. 591-619.

7. Weibull, W.A., "The Phenomenon of Rupture in Solids," Ingenoirs Vetenskaps Akadanien Handlinger, 1939, No. 153.

8. Batdorf, S.B. and Crose, J.G., "A Statistical Theory for the Fracture of Brittle Structures Subjected to Nonuniform Polyaxial Stresses", Joumal of Applied Mechanics, Vol. 41, No. 2, June 1974, pp. 459-464.

9. Batdorf, S.B., and Heinisch, H.L., Jr., Weakest Link Theory Reformulated for Arbitrary Fracture Criterion. Journal of the American Ceramic Society, Vol. 61, No. 7-8, July-Aug. 1978, pp. 355-358.

10. Palaniswamy, $\mathbf{K}$, and Knauss, W.G., On the Problem of Crack Extension in Brittle Solids Under General Loading, Mechanics Today, Vol. 4, 1978, pp. 87-148.

11. Shetty, D.R., Mixed-Mode Fracture Criteria for Reliability Analysis and Design with Structural Ceramics. Journal of Engineering for Gas Turbines and Power, Vol. 109, No. 3, July 1987, pp. 282-289.

12. Evans, AG., "A General Approach for the Statistical Analysis of Multiaxial Fracture", Journal of the American Ceramic Society, Vol. 61, 1978, pp 302-306.

13. Matsuo, Y., Trans. of the Japan Society of Mechanical Engineers, Vol. 46, 1980, pp. 605-611.

14. Evans, A.G., and Wiederhom, S.M., "Crack Propagation and Failure Prediction in Silicon Nitride at Elevated
Temperatures", Joumal of Material Science, Vol. 9, 1974, pp. 270-278.

15. Wiederhorn, S.M., Fracture Mechanics of Ceramics. Bradt, R.C., Hasselman, D.P., and Lange, F.F., eds., Plenum, New York, 1974, pp. 613-646.

16. Paris, P., and Erdogan, F., "A Critical Analysis of Crack Propagation Laws", Journal of Basic Engineering, Vol. 85, 1963, pp. 528-534.

17. Walker, K., "The Effect of Stress Ratio During Crack Propagation and Fatigue for 2024-T3 and 7075-T6 Aluminum", ASTM STP 462, 1970, pp. 1-14.

18. Dauskardt, R.H., James, M.R., Porter, J.R., and Ritchie, R.O., "Cyclic Fatigue Crack Growth in SiCWhisker-Reinforced Alumina Ceramic Composite: Long and Small Crack Behavior", Joumal of the American Ceramic Society, Vol. 75, No. 4, 1992, pp. 759-771.

19. Paris, P.C., and Sih, G.C., Stress Analysis of Cracks. ASTM STP 381, 1965, pp. 30-83.

20. Thiemeier, T., "Lebensdauervorhersage fun Keramische Bauteile Unter Mehrachsiget Beanspruchung", Ph.D. dissertation, University of Karlesruhe, Germany, 1989.

21. Sturmer, G., Schulz, A, and Wittig, S., "Lifetime Prediction for Ceramic Gas Turbine Components", ASME Preprint 91-GT-96, June 3-6, 1991.

22. Batdorf, S.B., "Fundamentals of the Statistical Theory of Fracture", Fracture Mechanics of Ceramics, Vol. 3, eds., Bradt, R.C., Hasselman, D.P.H. and Lange, F.F., Plenum Press, New York (1978), pp. 1-30.

23. Mencik, J., "Rationalized Load and Lifetime of Brittle Materials", Communications of the American Ceramic Society, Mar. 1984, pp. C37-C40.

24. Evans, A.G., "Fatigue in Ceramics", International Journal of Fracture, Dec. 1980 , pp. $485-498$.

25. Jakus, K., Coyne, D.C., and Ritter, J.E., Analysis of Fatigue Data for Lifetime Predictions for Ceramic Materials. Joumal of Material Science, Vol. 13, 1978, pp. 2071-2080.

26. Pai, S.S., and Gyekenyesi, J.P., Calculation of the Weibull Strength Parameters and Batdorf Flaw Density Constants for Volume and Surface-Flaw-Induced Fracture in Ceramics, NASA TM-100890, 1988.

27. Thoman, D.R, Bain, L.J, and Antle, C.E., Inferences on the Parameters of the Weibull Distribution. Technometrics, Vol. 11, No. 3, Aug. 1969, pp. 445-460. 
TABLE 1-Weibull parameters estimated from inert data.

\begin{tabular}{|c|c|c|c|c|c|}
\hline Specimen & $\begin{array}{c}\text { Weibull } \\
\text { modulus, } \\
\mathbf{m}_{\mathbf{s}}\end{array}$ & $\begin{array}{c}90 \% \text { confidence } \\
\text { bounds on } \\
\mathbf{m}_{s}\end{array}$ & $\begin{array}{c}\text { Characteristic } \\
\text { strength, } \\
\sigma_{\theta S} \\
\mathrm{MPa}\end{array}$ & $\begin{array}{c}90 \% \text { confidence } \\
\text { bounds on } \\
\sigma_{\text {es }} \\
\mathrm{MPa} \\
\end{array}$ & $\begin{array}{c}\text { Scale } \\
\text { parameter, } \\
\sigma_{\mathrm{os}} \\
\mathrm{MPa} \cdot \mathrm{mm}^{2 / \mathrm{m}_{\mathrm{r}}} \\
\end{array}$ \\
\hline $\begin{array}{l}\text { 3-point } \\
\text { 4-point } \\
\text { Disk } \\
\text { Disk (batch 2) }\end{array}$ & $\begin{array}{l}25.43 \\
23.76 \\
22.25 \\
28.98\end{array}$ & $\begin{array}{ll}20.47, & 29.91 \\
19.13, & 27.95 \\
17.12, & 26.81 \\
13.28, & 40.88\end{array}$ & $\begin{array}{l}385.9 \\
353.4 \\
338.7 \\
351.4\end{array}$ & $\begin{array}{ll}382.0, & 389.9 \\
349.6, & 357.3 \\
334.1, & 343.5 \\
341.5, & 362.2\end{array}$ & $\begin{array}{l}414.7 \\
425.8 \\
436.4 \\
423.2\end{array}$ \\
\hline
\end{tabular}

TABLE 2-Fatique parameters for 4-point bend bars.

\begin{tabular}{|c|c|c|c|c|c|}
\hline $\begin{array}{l}\text { Estimation } \\
\text { method }\end{array}$ & $\begin{array}{c}\text { Fatigue } \\
\text { constant, } \\
\mathbf{A}_{\mathrm{d}}\end{array}$ & $\begin{array}{c}\text { Fatigue } \\
\text { exponent, } \\
\mathbf{N}_{\mathbf{S}}\end{array}$ & $\begin{array}{c}\text { Fatigue } \\
\text { constant, } \\
\mathbf{B}_{\mathbf{w s}} \\
\mathrm{MPa}^{2} \cdot \mathbf{s}\end{array}$ & $\begin{array}{c}\text { Fatigue } \\
\text { constant, } \\
\mathbf{B}_{\mathrm{BS}} \\
\mathrm{MPa}^{2} \cdot \mathbf{s}\end{array}$ & $\begin{array}{c}\text { Crack } \\
\text { velocity, } \\
V_{c} \\
\mathbf{m} \cdot \mathbf{s}^{-1}\end{array}$ \\
\hline $\begin{array}{l}\text { Median Value } \\
\text { Least Squares } \\
\text { Med Deviation } \\
\text { Reference } 2\end{array}$ & $\begin{array}{c}2.339 \times 10^{2} \\
2.336 \times 10^{2} \\
2.337 \times 10^{2} \\
-\end{array}$ & $\begin{array}{l}36.04 \\
40.84 \\
41.23 \\
40.7\end{array}$ & $\begin{array}{c}4.590 \times 10^{-1} \\
5.631 \times 10^{-2} \\
4.783 \times 10^{-2} \\
-\end{array}$ & $\begin{array}{c}4.579 \times 10^{-1} \\
5.617 \times 10^{-2} \\
4.771 \times 10^{-2} \\
-\end{array}$ & $\begin{array}{l}1.162 \\
8.176 \\
9.373 \\
9.1 \\
\end{array}$ \\
\hline
\end{tabular}

TABLE 3-Fatique parameters for disk (batch 2) specimens.

\begin{tabular}{|c|c|c|c|c|}
\hline $\begin{array}{l}\text { Estimation } \\
\text { method }\end{array}$ & $\begin{array}{c}\text { Fatigue } \\
\text { constant, } \\
\mathbf{A}_{\mathbf{d}}\end{array}$ & $\begin{array}{c}\text { Fatigue } \\
\text { exponent, } \\
\mathbf{N}_{\mathbf{S}}\end{array}$ & $\begin{array}{c}\text { Fatigue } \\
\text { constant, } \\
\mathrm{B}_{\mathrm{BS}} \\
\mathrm{MPa}^{2} \cdot \mathrm{s} \\
\end{array}$ & $\begin{array}{c}\begin{array}{c}\text { Crack } \\
\text { velocity, } \\
V_{c} \\
\text { m } \cdot \mathbf{s}^{-1}\end{array} \\
\end{array}$ \\
\hline $\begin{array}{l}\text { Median Value } \\
\text { Least Squares } \\
\text { Med Deviation } \\
\text { Reference } 2\end{array}$ & $\begin{array}{c}2.293 \times 10^{2} \\
2.313 \times 10^{2} \\
2.304 \times 10^{2} \\
-\end{array}$ & $\begin{array}{l}35.68 \\
41.79 \\
36.23 \\
36.6\end{array}$ & $\begin{array}{c}2.675 \times 10^{-1} \\
3.959 \times 10^{-2} \\
2.649 \times 10^{-1} \\
-\end{array}$ & $\begin{array}{c}1.894 \\
16.22 \\
1.988 \\
2.4 \\
\end{array}$ \\
\hline
\end{tabular}


TABLE 4-Comparison of 4-point and disk (batch 2) characteristic strengths

\begin{tabular}{|c|c|c|c|}
\hline $\begin{array}{l}\text { Stressing } \\
\text { rate, }\end{array}$ & $\begin{array}{l}\text { 4-point } \\
\text { strength, }\end{array}$ & $\begin{array}{c}\text { Disk } \\
\text { strength, }\end{array}$ & $\begin{array}{c}\text { Strength } \\
\text { ratio, } \\
\text { en } \sigma_{\theta s_{\text {at }}}\end{array}$ \\
\hline$\sigma$ & $\sigma_{\theta S}$ & ${ }_{0 S}$ & $\ln \sigma_{B S_{4}}$ \\
\hline $\mathrm{MPa} \cdot \mathrm{s}^{-1}$ & $\mathrm{MPa}$ & $\mathrm{MPa}$ & \\
\hline 0.020 & $2.145 \times 10^{2}$ & $2.116 \times 10^{2}$ & 0.9975 \\
\hline 0.100 & $2.250 \times 10^{2}$ & $2.195 \times 10^{2}$ & 0.9954 \\
\hline 10.00 & $2.531 \times 10^{2}$ & $2.492 \times 10^{2}$ & 0.9972 \\
\hline 100.0 & $2.628 \times 10^{2}$ & $2.620 \times 10^{2}$ & 0.9995 \\
\hline Inert & $3.534 \times 10^{2}$ & $3.514 \times 10^{2}$ & 0.9990 \\
\hline
\end{tabular}

TABLE 5-Weibull parameters estimated in water (1 MPa/s).

\begin{tabular}{lcccc}
\hline Specimen & $\begin{array}{c}\text { Weibull } \\
\text { modulus, } \\
\mathbf{m}_{d S}\end{array}$ & $\begin{array}{c}90 \% \text { confidence } \\
\text { bounds on } \\
\mathbf{m}_{\mathrm{dS}}\end{array}$ & $\begin{array}{c}\text { Characteristic } \\
\text { strength, } \\
\sigma_{\theta s} \\
\mathrm{MPa}\end{array}$ & $\begin{array}{c}90 \% \text { confidence } \\
\text { bounds on } \\
\sigma_{\theta S}\end{array}$ \\
\hline 3-point & 27.83 & $21.20,33.70$ & 255.6 & $\mathbf{M P a}$ \\
4-point & 26.70 & $20.54,32.17$ & 236.3 & $252.7,258.5$ \\
Disk & 32.66 & $24.87,39.53$ & 215.9 & $213.8,218.1$ \\
\hline
\end{tabular}




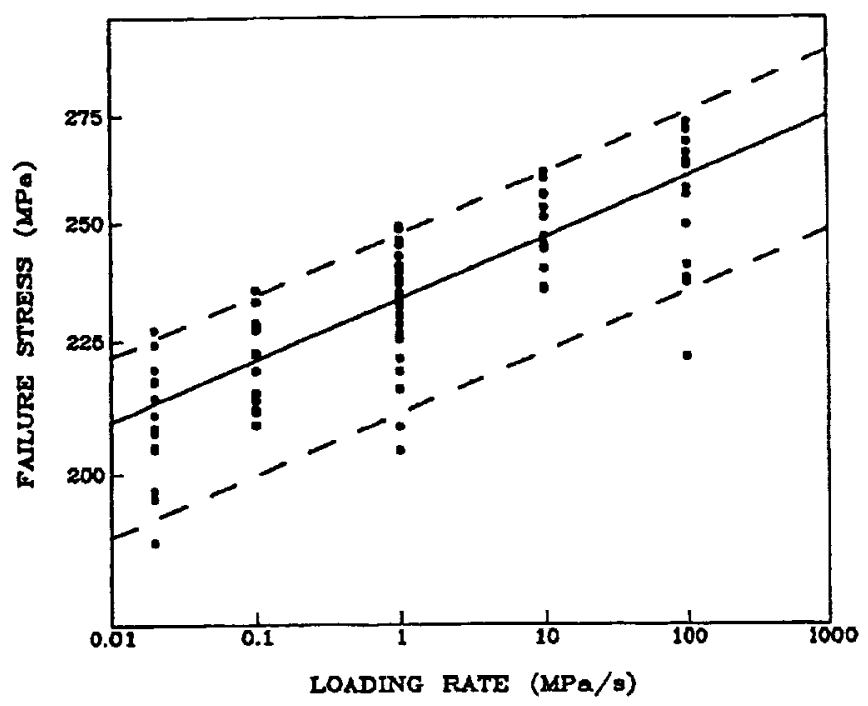

Figure 1.-Dynamic fatigue of alumina four-point flexure bars in water. Median regression line (solid), and $5 \%$ and $95 \%$ regression lines (dashed) estimated with the median deviation technique.

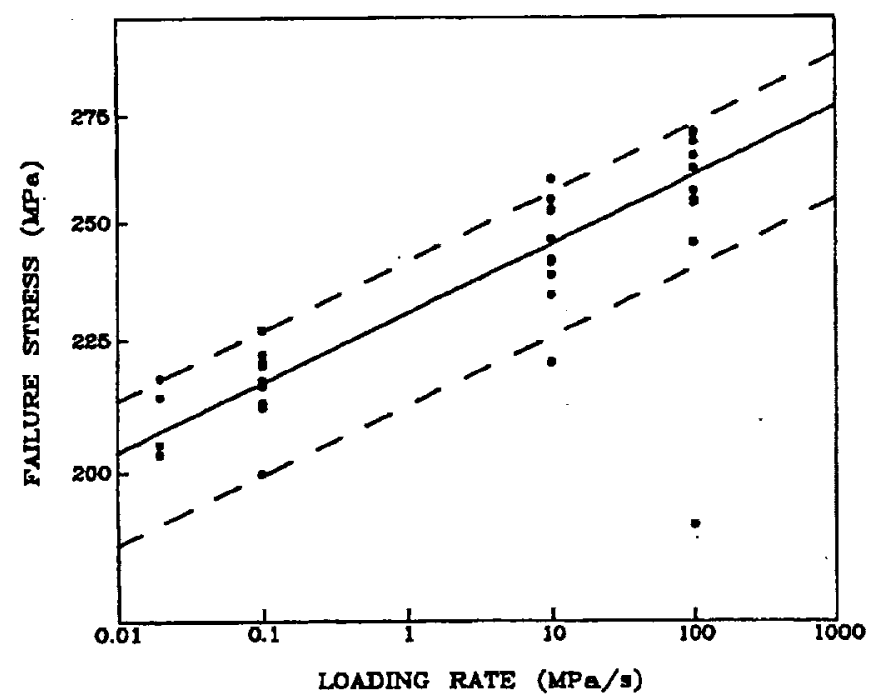

Figure 2.-Dynamic fatigue of alumina pressure-on-disk flexure specimens in water. Median regression line (solid), $5 \%$ and $95 \%$ regression lines (dashed) estimated with the median deviation technique.

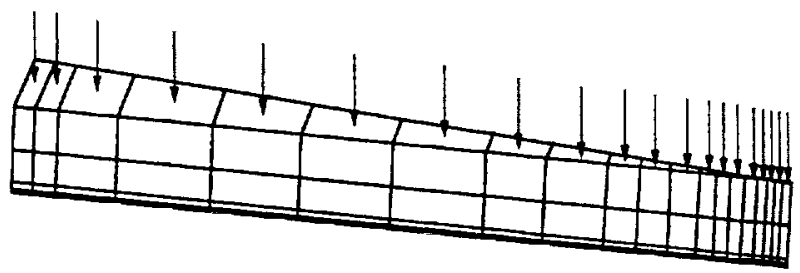

Figure 3.-Finite element model of a $7.5^{\circ}$ sector of the disk. Arrows indicate pressure load on disk.

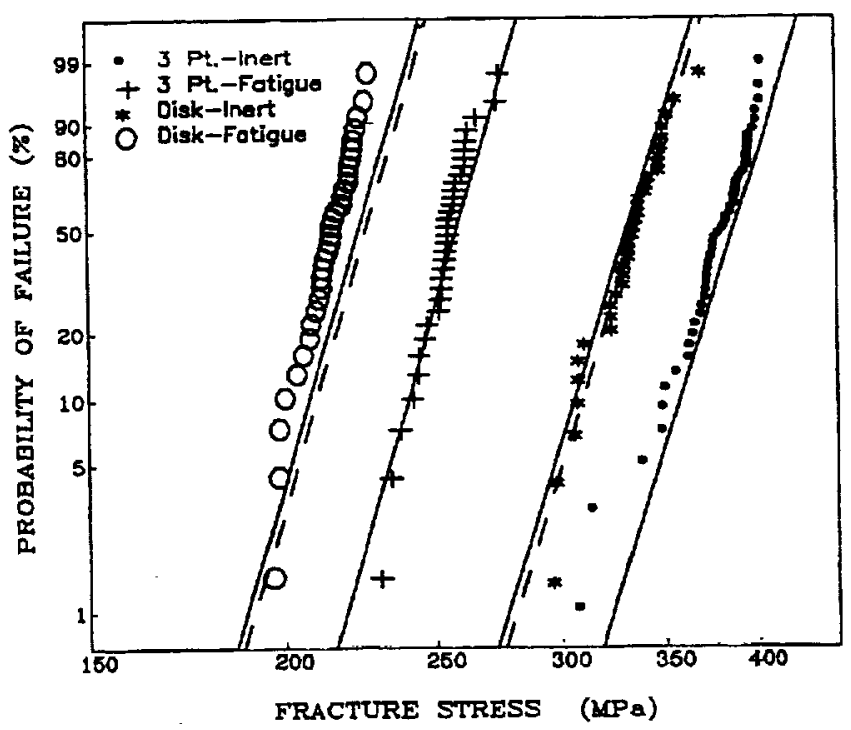

Figure 4.-Weibull plot showing fast-fracture three-point and disk specimen strengths measured in an inert environment, as well as three-point and disk specimen tracture strengths dynamically loaded at a rate of $1 \mathrm{MPa} / \mathrm{s}$. Solid lines are corresponding CARES/LIFE predictions for $\overline{\mathrm{C}}=0.82$. Dashed lines are corresponding predictions from reference 2 .

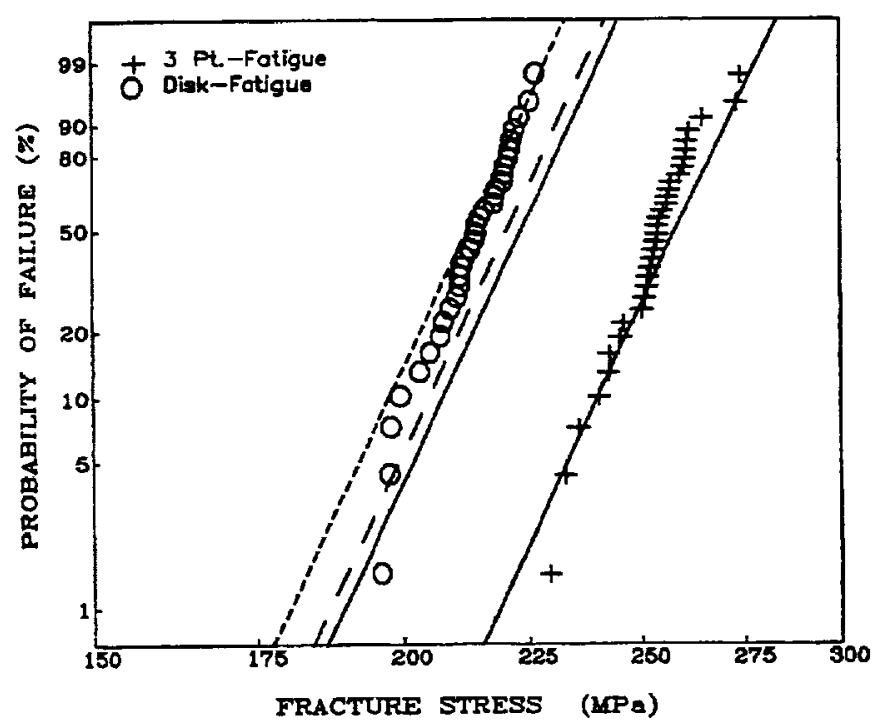

Figure 5.-Weibull plot showing three-point and disk specimen dynamic fatigue strengths that were loaded at a rate of $1 \mathrm{MPa} / \mathrm{s}$. Solid line corresponds to CARES/LIFE prediction for $\bar{C}=0.82$ (shear-sensitive criterion). Long dashed line corresponds to the disk prediction for $\bar{C}=0.90$ and the short dashed line corresponds to the disk prediction for $\bar{C} \gg 1.0$ (shear-insensitive criterion). 
Public reporing burden for this collection of information is estimated to average 1 hour per response, including the time lor reviewing instructions, searching existing data sources, gathering and maintaining the data needed, and completing and reviewing the collection of intormation. Send comments regarding this burden estimate or any other aspect of this collection of information, including suggestions for reducing this burden, to Wash ington Headquarters Services. Directorate for Information Operations and Reports, 1215 Jefferson Davis Highway, Suite 1204, Arlington. VA 2202-4302, and to the OHice of Management and Budget, Paperwork Reduction Project (0704-0188), Washington. DC 20503.

\begin{tabular}{|l|l|r|}
\hline 1. AGENCY USE ONLY (Leave blank) & $\begin{array}{c}\text { 2. REPORT DATE } \\
\text { January } 1994\end{array}$ & $\begin{array}{r}\text { 3. REPORT TYPE AND DATES COVERED } \\
\text { Technical Memorandum }\end{array}$ \\
\hline
\end{tabular}

4. TITLE AND SUBTILE

Durability Evaluation of Ceramic Components Using CARES/LIFE

6. AUTHOR(S)

Noel N. Nemeth, Lynn M. Powers, Lesley A. Janosik, and John P. Gyekenyesi

\section{FUNDING NUMBERS}

WU-505-63-5B
7. PERFoRMung ORGANIZATION NAME(S) AND ADDRESS(ES)

National Aeronautics and Space Administration

Lewis Research Center

Cleveland, Ohio 44135-3191

9. SPONSOAING/MONITORING AGENCY NAME(S) AND ADDRESS(ES)

National Aeronautics and Space Administration

Washington, D.C. 20546-0001
8. PERforming ORganization REPORT NUMBER

E-8402

10. SPONSORINGMONITORING AGENCY REPORT NUMBEA

NASA TM-106475

\section{SUPPLEMENTARY NOTES}

Prepared for the 39th International Gas Turbine and Aeroengine Congress sponsored by the American Society of Mechanical Engineers, The Hague, The Netherlands, June 13-16, 1994. Noel N. Nemeth, Lesley A. Janosik, and John P. Gyckenyesi. NASA Lewis Research Center and Lynn M. Powers, Cleveland State University, Deparment of Civil Engineering. Cleveland, Ohio 44115. Responsible person, Noel N. Nemeth, organization code 5250, (216) 433-3215.

12a. DISTRIBUTIONAVAILABILTY STATEMENT

12b. DISTRIBUTION CODE

Unclassified - Unlimited

Subject Categories 27 and 39

13. ABSTRACT (Maximum 200 words)

The computer program CARES/LIFE calculates the time-dependent reliability of monolithic ceramic components subjected to thermomechanical and/or proof test loading. This program is an extension of the CARES (Ceramics Analysis and Reliability Evaluation of Structures) computer program. CARES/LIFE accounts for the phenomenon of subcritical crack growth (SCG) by utilizing the power law, Paris law, or Walker equation. The two-parameter Weibull cumulative distribution function is used to characterize the variation in component strength. The effects of multiaxial stresses are modeled using either the principle of independent action (PIA), the Weibull normal stress averaging method (NSA), or the Batdorf theory. Inert strength and fatigue parameters are estimated from rupture strength data of naturally flawed specimens loaded in static, dynamic, or cyclic fatigue. Application of this design methodology is demonstrated using experimental data from alumina bar and disk flexure specimens which exhibit SCG when exposed to water.

14. SUBJECT TERMS

\begin{tabular}{|c|c|}
\hline & $\begin{array}{c}\text { 15. NUMBER OF PAGES } \\
15\end{array}$ \\
\hline & $\begin{array}{r}\text { 16. PRICE CODE } \\
\mathrm{AO} 3\end{array}$ \\
\hline $\begin{array}{l}\text { 19. SECURITY CLASSIFICATION } \\
\text { OF ABSTRACT } \\
\text { Unclassified }\end{array}$ & 20. LIMTTATION OF ABSTRACT \\
\hline
\end{tabular}

Fatigue; Weibull; Batdorf; Reliability; Ceramic; Design

17. SECURTYY CLASSIFICATION OF REPORT

Unclassified
18. SECURTIY CLASSIFICATION OF THIS PAGE

Unclassified 